\title{
Prevalence of fragility fractures according to quality and outcomes framework (QOF) of the general medical services (GMS) contract and quality
} initiatives to improve osteoporosis care in the general practice within Caerphilly County Borough, Wales, UK: a feasibility study

\begin{abstract}
Introduction: Osteoporosis is defined as a reduction in bone mineral density resulting in reduced bone strength and increase the risk of fractures. Osteoporosis is a silent condition and often diagnosed following a fracture which has a huge impact on person's life. The aim of this feasibility study was to measure the prevalence of fragility fractures in all patients above 50 years of age according to Quality and Outcomes Framework (QOF) of the General Medical Services (GMS) contract and apply quality improvement methodology to improve osteoporosis care.

Method: This was a retrospective observational study to complete analysis for all known patients above age 50 years with diagnosed osteoporosis, known fragility fracture or prescribed osteoporosis treatment according to a General Practice database. General Practice staff was actively involved to implement quality initiatives. The pilot study was classed as service evaluation project according to health research authority decision tool

Results: The practice has 6300 patients on 1 st Oct 2017 and 320 were included but 6 patients were excluded. Analysis was completed for 314 patients. The mean age of studied cohort (above 50 years age) was $75.5 \pm 10.5$ years and $66.9 \%(210 / 314)$ were female. Mean number of co-morbidities for the studied population was $4.4 \pm 2.8$. $66 \%(208 / 314)$ patients were on polypharmacy and the mean number of drugs was 6.8 \pm 4.2 . $45.5 \%(143 / 314)$ had recorded fracture and of that $83 \%(116 / 140)$ were classed as a fragility fracture (vertebra, wrist, hip, humorous and pelvis). 89 patients were on osteoporosis drugs, $44 \%(51 / 116)$ patients diagnosed fragility fractures were on appropriate treatment. $33.4 \%$ (40/116) patients were not treated according to guidance and $7.3 \%(23 / 314)$ were prescribed osteoporosis drugs inappropriately. $43.6 \%(137 / 314)$ patients were discussed as part of quality initiatives and were treated to guidance.

Conclusion: This study suggests that an average practice of 6000 patients could have $2 \%$ prevalence of fragility fractures and one-third may not be treated to guidance. Regular monitoring of practice data and implementing quality initiatives enhance autonomous osteoporosis care by general practice doctors. Similar intervention is needed more widely to prevent a second fracture.
\end{abstract}

Keywords: fragility fractures, outcome, second fracture, quality improvement

\section{Introduction}

Osteoporosis is defined as a reduction in the bone mineral density (BMD) and disruption of bone architecture, resulting in reduced bone strength which increases the risk of fractures with minimal impact or following a fall from a standing or sitting height. The incidence of osteoporotic fractures is rising worldwide and is now recognised as
Volume 3 Issue 2 - 2018

Inderpal Singh,' Anser Anwar,, Aman Rasuly, ${ }^{2}$ Chris Edwards, ${ }^{3} \mathrm{AH}$ Farooq, ${ }^{4} \mathrm{~S}$ Majeed, ${ }^{4}$ Nitu Singh, ${ }^{4}$ A Waheed ${ }^{4}$

'Department of Geriatric Medicine, Aneurin Bevan University Health Board, UK

${ }^{2}$ Department of Acute Medicine and Geriatrics, Aneurin Bevan University Health Board, UK

${ }^{3}$ Consultant Clinical Scientist, Aneurin Bevan University Health Board,Wales UK

${ }^{4}$ General Practitioner, Pontllanfraith Health Centre, UK

Correspondence: Inderpal Singh, Consultant Geriatrician, Department of Geriatric Medicine,Ysbyty Ystrad Fawr,Ystrad Mynach, Aneurin Bevan University Health Board CF82 7EP, UK, Fax (0044) I 44380243I, Tel +(0044) I443802234, Email Inder.Singh@wales.nhs.uk

Received: December 12, 2018| Published: March 01, 2018 
According to the National Hip Fracture Data (NHFD), the mean length of stay following a hip fracture is 21.6 days and an overall 30-day mortality rate of $6.7 \%$ for $2016 .^{2}$ One-third of patients could die during the following year after hip fracture. ${ }^{3}$ The risk of future fragility fractures increases with the number of previous fractures of the hip, spine or wrist, independently of age. ${ }^{4}$ Prevalent fractures predict a risk of subsequent fracture even in individuals with normal BMD and osteopenia, and excess mortality particularly for those with osteopenia and osteoporosis. ${ }^{5}$

The incidence of osteoporotic fractures is higher amongst women and this has been related to the gonadal insufficiency in the postmenopausal phase. However, there are marked geographic distributions in the incidence of osteoporotic fractures within communities which could be related to other factors related to lifestyles, ecology or environment. There are medical conditions like stroke, ${ }^{6,7}$ dementia and parkinsonism ${ }^{8,9}$ have a higher risk of fragility fractures due to higher bone loss and a higher risk of falls. Screening for osteoporosis should be considered in high-risk patients ${ }^{7,8}$ and therapeutic interventions should be considered as per guidance. ${ }^{10}$ A quality improvement (QI) methodology based on the model of improvement, Plan-Do-Study-Act (PDSA) cycles in people with parkinsonism showed a $56 \%$ increase in treating underlying osteoporosis according to guidance. ${ }^{11}$

The primary aim of this feasibility study was to measure the prevalence of fragility fractures in all patients above 50 years of age according to Quality and Outcomes Framework (QOF) of the General Medical Services (GMS) contract $^{12}$ in a relatively low socio-economic status and well defined geographic population in Caerphilly County Borough, Wales, UK. Our secondary aim was to complete descriptive analysis of the population and study the co-morbidity burden and bridge the gaps in the evidence-based osteoporosis treatment in the General Practice by applying quality improvement methodology to improve patient care.

\section{Methods}

\section{Study design}

This retrospective observational study was conducted to complete descriptive analysis for all patients who are on osteoporosis treatment or have known osteoporosis or have sustained a fragility fracture according the General Practice read codes (fragility fracture - XaNSP; fragility fracture due to unspecified osteoporosis - XaIIP, referral for dual-energy X-ray absorptiometry (DXA) scan - XaI85; DXA scan result - XaITW or XaPE2 or XaITb and Osteoporosis - N330).

\section{Setting}

This is a feasibility study which was done in a General Practice which serves a relatively low socio-economic status and well defined stable geographic population in Caerphilly County Borough, Wales, UK. A total number of patients registered with the practice were 6300 at the time of start of the study. All patients above the age of 50 years on $01 / 10 / 2017$ who have a diagnosis of osteoporosis, history of fracture, known fragility fracture, osteoporosis diagnosed on (DXA) scan or on osteoporosis drugs were included. In addition known patients with dementia, stroke or Parkinsonism were also included considering the relatively high risk of falls and higher prevalence of osteoporosis. ${ }^{6-9,13,14}$

\section{Data and measurements}

Data were obtained from General Practice database and from Clinical Work Station between 1st October 2017 and 30th October 2017 for all patients above 50 years of age. General Practice colleagues and practice staff were also involved to provide more information on social circumstances like living alone with partner/spouse, needing help with basic activities of daily living including help with shopping and medications. Fragility fracture was defined as any fracture reported in the practice database as low impact fracture involving vertebra, wrist, hip, humerus and pelvis. Other fractures including ribs, ankle, distal tibia and fibula were included as all fractures. Data were transcribed, anonymised and incorporated into one password protected Microsoft Excel sheet.

\section{Quality initiatives}

Prudent healthcare principles set out by the Bevan Commission were planned to employ for implementing quality improvement initiatives.$^{15}$ Low impact fractures in older people above 75 years of age are deemed as fragility fractures and should be treated to guidance. ${ }^{10,12}$ Therefore, sub-analysis of the fragility fracture was done to understand the relationship of fracture to co-morbidities, drugs, sex and arbitrary age groups of less than or more than 75 years old in the practice cohort to ensure quality initiatives were taken for those at higher risk, with the greatest health need first. ${ }^{15}$ General Practitioners (GP) and practice staff were involved to best use the existing resources in the community and applying coproduction principles..$^{15}$ All patients who were deemed to be on inappropriate drugs or at higher risk of subsequent fracture were discussed in the consultant led case based discussion (CBD) with GP and practice staff to ensure not only a person-centred care but also an all-inclusive approach to reduce inappropriate variation through evidence-based approaches. ${ }^{15}$ The rationale to employ CBD for high-risk patients was agreed as this intervention had proven to be effective, was based on the model of improvement, Plan-Do-Study-Act (PDSA) and had shown improvement in treating underlying osteoporosis according to guidance for patients attending the Movement Disorder clinic. ${ }^{11} \mathrm{~A}$ $50 \%$ improvement in osteoporosis care in the current practice was agreed.

\section{Statistical analysis}

All statistics were conducted using STATISTICA StatSoft data analysis software system, version 9.1 (StatSoft, Inc., 2010, Tulsa, OK, USA). Means \pm standard deviations were calculated for baseline characteristics of all patients. T-tests were used to compare mean baseline characteristics of patients, and chi-square tests were used to compare categorical variables. $\mathrm{P}$-values $\leq 0.05$ were taken to be statistically significant.

\section{Ethical approval}

This pilot study was classed as a service evaluation project according to the Health Research Authority decision tool. The study plan was submitted to the Aneurin Bevan University Health Board (ABUHB) Research and Development (R \& D) department, which approved the project as an observational service evaluation with no requirement for ethical approval (ABUHB R\&D Reference Number: SA/791/17). All demographic and outcome data incorporated into the study were routinely documented in the clinical workstation 
or the General Practice dataset which operates under ABUHB. No identifiable patient information has been or will be shared.

\section{Results}

The practice had 6300 patients registered on 1st October 2017. 320 patients who met the inclusion criteria were included. Six patients were excluded as they have been registered to another general practice and data was not available, therefore analysis was completed for 314 patients.

\section{Description of the practice population}

The mean age of studied cohort (above 50 years) was $75.5 \pm 10.5$ years and $66.9 \%(n=210 / 314)$ were females. Mean number of comorbidities for the studied population was $4.4 \pm 2.8,66 \%(n=208 / 314)$ patients were on polypharmacy and the mean number of drugs were $6.8 \pm 4.2$ (range $=0-29) .11 .5 \%$ patients $(n=36 / 314)$ patients were in Care Homes. The prevalence of stroke, dementia and Parkinsonism in the studied high risk general practice population was $32.8 \%$ $(n=103 / 314), 12.7 \%(n=40 / 314)$, and $4.1 \%(n=13 / 314)$ respectively.

The T-test for independent groups was used to explore differences in mean numbers of comorbidities and number of drugs between groups who had fracture versus groups who had no fractures. For all fractures the mean number of co-morbidities and mean number of drugs were $4.89 \pm 3.3$ and $7.35 \pm 4.2$ respectively. The mean number of comorbidities and drugs for the group with no fractures was $4.08 \pm 2.15(\mathrm{p}=0.01)$ and $6.36 \pm 4.2(\mathrm{p}=0.04)$ respectively. This shows that the patients who experienced any fractures had significantly more comorbidities and higher number of drugs. However there was no statistically significant difference in the mean number of comorbidities or drugs in those with first fragility fracture or no fracture.

\section{Prevalence of fracture in practice}

314 patients above 50 years met the inclusion criteria including diagnosis of osteoporosis, any fracture, known fragility fracture, osteoporosis diagnosed on DXA scan, on osteoporosis drugs or classed as a higher risk of falls and fracture. $45.5 \%(n=143 / 314)$ had recorded fracture and of those $83 \%(n=116 / 140)$ will be classed as fragility fractures to include vertebral, wrist, hip, humerus and pelvis. Mean age of patients who sustained first fragility fracture was $71.1 \pm 10.6$ years (range $=41-92$ years, median age $=71$ years). The sites of fractures were vertebra $39.9 \%(n=57 / 143)$, wrist $21.7 \%$ $(n=31 / 143)$, hip/Femur 9.8\% $(n=14 / 143)$, humerus 5.6\% $(n=8 / 143)$, pelvis $4.2 \%(n=6 / 143)$, ankle/distal fibula $7.0 \%(n=10 / 143)$ and others $11.9 \%(\mathrm{n}=17 / 143)$.

89 patients were on osteoporosis drugs. $44 \%(n=51 / 116)$ patients who have diagnosed fragility fracture were on appropriate osteoporosis medications. Overall $30 \%(n=27 / 89)$ had been prescribed drugs for more than 5 years and mean duration of drugs prescribed was 3.8 years $($ Median $=1.7$ years and range $=0.1-18.8$ years $) .19 \%(17 / 89)$ were still on treatment for more than 5 years at the time of review. $34.4 \%(\mathrm{n}=40 / 116)$ patients were not treated to guidance and $21.5 \%$ $(\mathrm{n}=25 / 116)$ patients were deemed not appropriate for bone protection at the time of review and were either on drug holiday or DXA showed Osteopenia.

$33.5 \%$ patients $(n=47 / 140)$ sustained a new second fracture after mean duration of $4.0 \pm 4.1$ years (range $=0$ - 16 years, median $=3$ years). $81 \%(n=38 / 47)$ will be classed as fragility fractures, $19 \%(n=9 / 47)$ were hip fractures and one-third $(n=3 / 9)$ were not on appropriate treatment. $24 \%(\mathrm{n}=9 / 38)$ had a second fragility fracture within 12 months. Another $25.5 \%(\mathrm{n}=12 / 47)$ sustained a third fracture after a mean duration of $2.2 \pm 2.3$ years (range $=0-9$ years, median $=1.6$ years).

Sub-analysis of the prevalence of the fractures and proportion not treated to guidance was done according to advancing age. Results are shown in Table 1. There was no significant difference in the proportion of patients treated to guidance if above 75 years of age $(39 \%, 27 / 69)$ or below 75 years $(29 \%, 14 / 48)(\mathrm{p}=0.26)$.

Table 1 Sub-analysis of the prevalence of the fractures according to advancing age.

\begin{tabular}{|c|c|c|c|c|c|}
\hline Age group & $\begin{array}{l}\text { All patients }>50 \text { years } \\
\mathrm{N}=314\end{array}$ & $\begin{array}{l}50-65 \text { years } \\
N=55\end{array}$ & $\begin{array}{l}65-75 \text { years } \\
N=100\end{array}$ & $\begin{array}{l}\text { 75-85 years } \\
\mathrm{N}=94\end{array}$ & $\begin{array}{l}\text { Above } 85 \\
N=65\end{array}$ \\
\hline All fractures \% (n) & $\begin{array}{l}45.5 \% \\
(143 / 314)\end{array}$ & $\begin{array}{l}30.9 \% \\
(17 / 55)\end{array}$ & $\begin{array}{l}47 \% \\
(47 / 100)\end{array}$ & $\begin{array}{l}46.8 \% \\
(44 / 94)\end{array}$ & $\begin{array}{l}55.4 \% \\
(36 / 65)\end{array}$ \\
\hline $1^{\text {st }}$ Fragility fracture $\%(n)$ & $\begin{array}{l}37 \% \\
(116 / 314)\end{array}$ & $\begin{array}{l}20 \% \\
(11 / 55)\end{array}$ & $\begin{array}{l}37 \% \\
(37 / 100)\end{array}$ & $\begin{array}{l}41.5 \% \\
(39 / 94)\end{array}$ & $\begin{array}{l}46.2 \% \\
(30 / 65)\end{array}$ \\
\hline Patients not treated to guidance $\%$ (n) & $\begin{array}{l}34.5 \% \\
(40 / 116)\end{array}$ & $\begin{array}{l}27 \% \\
(3 / 11)\end{array}$ & $\begin{array}{l}30 \% \\
(11 / 37)\end{array}$ & $\begin{array}{l}36 \% \\
(14 / 39)\end{array}$ & $\begin{array}{l}43 \% \\
(13 / 30)\end{array}$ \\
\hline $2^{\text {nd }}$ Fragility fracture $\%(n)$ & $\begin{array}{l}29 \% \\
(34 / 116)\end{array}$ & $\begin{array}{l}27 \% \\
(3 / 11)\end{array}$ & $\begin{array}{l}19 \% \\
(7 / 37)\end{array}$ & $\begin{array}{l}28 \% \\
(11 / 39)\end{array}$ & $\begin{array}{l}43 \% \\
(13 / 30)\end{array}$ \\
\hline Mean duration to second fragility fracture years & 4.0 & 4.2 & 1.5 & 4.8 & 5.2 \\
\hline Patients not treated to guidance after $2^{\text {nd }}$ fracture $\%$ (n) & $\begin{array}{l}32 \% \\
(11 / 34)\end{array}$ & $\begin{array}{l}66.6 \% \\
(2 / 3)\end{array}$ & $\begin{array}{l}14 \% \\
(1 / 7)\end{array}$ & $\begin{array}{l}27 \% \\
(3 / 11)\end{array}$ & $\begin{array}{l}38 \% \\
(5 / 13)\end{array}$ \\
\hline $3^{\text {rd }}$ Fragility fracture $\%(n)$ & $\begin{array}{l}23.5 \% \\
(8 / 34)\end{array}$ & $\begin{array}{l}33 \% \\
(1 / 3)\end{array}$ & $\begin{array}{l}14 \% \\
(1 / 7)\end{array}$ & $\begin{array}{l}18 \% \\
(2 / 11)\end{array}$ & $\begin{array}{l}38 \% \\
(5 / 13)\end{array}$ \\
\hline Mean duration of second fragility fracture \% (n) & 1.3 & 0.8 & 0.2 & 2.2 & 1.5 \\
\hline Patients not treated to guidance after $2^{\text {nd }}$ fracture $\%$ (n) & $\begin{array}{l}25 \% \\
(2 / 8)\end{array}$ & On treatment & NA & $\begin{array}{l}50 \% \\
(1 / 2)\end{array}$ & $\begin{array}{l}40 \% \\
(2 / 5)\end{array}$ \\
\hline
\end{tabular}


All patients were also divided into two arbitrary groups for sub-analysis by age $<75$ years versus $>75$ years by computing the prevalence as a number with fracture divided by numbers in those age groups. All proportions showed more fractures for the $>75$ years group, with the first fragility fracture numbers large enough to show statistical significance $(\mathrm{p}=0.02)$ (Table 2$)$. Sub-analysis were also done for sex in the age group between $<75$ years and $>75$ years. It showed that only females above 75 years have a significantly higher risk of all fractures, first fragility and second fragility fractures. There was no significant difference in men above or below 75 years of age (Table 2).

Sub-analysis of the prevalence of the fractures was also done according to the high risk of falls including stroke, dementia and
Parkinsonism. Data were analysed by grouping all patients into two groups: high-risk group (diagnosis of stroke, dementia or Parkinsonism) and low risk (absence of these three conditions). This shows that the low-risk group had a higher prevalence of fractures than the high-risk group, being highly significantly different for all fractures, first fragility fracture and second fragility fracture (Table 3 ).

In addition, these data also show that for all sexes and for females in the low-risk group had significantly fewer fractures and $1^{\text {st }}$ fragility fractures than the group with assumed high-risk factors. For $2^{\text {nd }}$ and $3^{\text {rd }}$ fragility fractures, this difference becomes insignificant (supplementary data analyses available if needed). This result warrants further investigation of other potentially confounding or influential factors.

Table 2 Prevalence of the fractures according to age (below and above 75 years) and sex.

\begin{tabular}{|c|c|c|c|c|c|c|c|c|c|}
\hline & Both Sexes & & $\begin{array}{l}\text { Difference } \\
\text { between } \\
\text { proportions } \\
\text { p value* }\end{array}$ & Females & & $\begin{array}{l}\text { Difference } \\
\text { between } \\
\text { proportions } \\
\text { p value* }\end{array}$ & Males & & $\begin{array}{l}\text { Difference } \\
\text { between } \\
\text { proportions } \\
\text { p value* }\end{array}$ \\
\hline \multirow{2}{*}{ Age Group } & $<75$ years & $>75$ years & & $<75$ years & $>75$ years & & $<75$ years & $>75$ years & \\
\hline & $\mathrm{N}=155$ & $\mathrm{~N}=159$ & & $\mathrm{~N}=100$ & $\mathrm{~N}=110$ & & $\mathrm{~N}=55$ & $\mathrm{~N}=49$ & \\
\hline $\begin{array}{l}\text { All fractures } \\
\%(N)\end{array}$ & $\begin{array}{l}41.3 \% \\
(64 / 155)\end{array}$ & $50.3 \%(80 / 159)$ & 0.11 & $44 \%(44 / 100)$ & $\begin{array}{l}57.3 \% \\
(63 / 110)\end{array}$ & 0.05 & $34.5 \%(19 / 55)$ & $\begin{array}{l}(17 / 49) \\
34.7 \%\end{array}$ & 1.0 \\
\hline $\begin{array}{l}\text { 1st fragility } \\
\text { fracture }\end{array}$ & $\begin{array}{l}31 \% \\
(48 / 155)\end{array}$ & $43.4 \%(69 / 159)$ & 0.02 & $36 \%(36 / 100)$ & $\begin{array}{l}50.9 \% \\
(56 / 110)\end{array}$ & 0.03 & $20 \%(11 / 55)$ & $\begin{array}{l}(13 / 49) \\
26.5 \%\end{array}$ & 0.43 \\
\hline $\begin{array}{l}\text { 2nd fragility } \\
\text { fracture }\end{array}$ & $\begin{array}{l}20.8 \% \\
(10 / 48)\end{array}$ & $34.8 \%(24 / 69)$ & 0.1 & $19.4 \%(7 / 36)$ & $\begin{array}{l}44.6 \% \\
(25 / 56)\end{array}$ & 0.01 & $7.2 \%(4 / 11)$ & $\begin{array}{l}01-02- \\
201315.4 \%\end{array}$ & 0.53 \\
\hline $\begin{array}{l}\text { 3rd fragility } \\
\text { fracture }\end{array}$ & $\begin{array}{l}20 \% \\
(2 / 10)\end{array}$ & $29.2 \%(7 / 24)$ & 0.56 & $28.5 \%(2 / 7)$ & $\begin{array}{l}32 \% \\
(8 / 25)\end{array}$ & 0.86 & $0 \%(0 / 4)$ & $\begin{array}{l}\text { 01-01- } \\
20138 \%\end{array}$ & 0.56 \\
\hline
\end{tabular}

${ }^{*}$-value computed from a difference in proportions test.

Table 3 Sub-analysis of the prevalence of the fractures according to risk factor.

\begin{tabular}{|c|c|c|c|c|c|}
\hline \multirow[t]{2}{*}{ Risk factor } & \multirow[t]{2}{*}{$\begin{array}{l}\text { Low-risk } \\
\text { group } \\
(n=164)\end{array}$} & \multicolumn{3}{|c|}{$\begin{array}{l}\text { High-risk group } \\
(n=156)\end{array}$} & \multirow[t]{2}{*}{$\begin{array}{l}\text { P-value low risk Vs high } \\
\text { risk* }\end{array}$} \\
\hline & & $\begin{array}{l}\text { Stroke } \\
(\mathrm{n}=103)\end{array}$ & $\begin{array}{l}\text { Dementia } \\
(\mathrm{n}=40)\end{array}$ & $\begin{array}{l}\text { Parkinsonism } \\
(\mathrm{n}=13)\end{array}$ & \\
\hline All fractures \% (n) & $\begin{array}{l}58.5 \% \\
(96 / 164)\end{array}$ & $\begin{array}{l}26.2 \% \\
(27 / 103)\end{array}$ & $\begin{array}{l}37.5 \% \\
(15 / 40)\end{array}$ & $\begin{array}{l}46.2 \% \\
(6 / 13)\end{array}$ & $\mathrm{p}<0.001$ \\
\hline 1st Fragility fracture $\%(n)$ & $\begin{array}{l}51.8 \% \\
(85 / 164)\end{array}$ & $\begin{array}{l}15.5 \% \\
(16 / 103)\end{array}$ & $\begin{array}{l}30 \% \\
(12 / 40)\end{array}$ & $\begin{array}{l}30.8 \% \\
(4 / 13)\end{array}$ & $\mathrm{p}<0.001$ \\
\hline Patients not treated to guidance $\%$ (n) & $(23 / 85)$ & $\begin{array}{l}56 \% \\
(9 / 16)\end{array}$ & $\begin{array}{l}58 \% \\
(7 / 12)\end{array}$ & $\begin{array}{l}50 \% \\
(2 / 4)\end{array}$ & \\
\hline 2nd Fragility fracture \% (n) & $\begin{array}{l}35.3 \% \\
(30 / 85)\end{array}$ & $\begin{array}{l}6 \% \\
(1 / 16)\end{array}$ & $\begin{array}{l}33 \% \\
(4 / 12)\end{array}$ & $\begin{array}{l}25 \% \\
(1 / 4)\end{array}$ & $\mathrm{p}<0.001$ \\
\hline $\begin{array}{l}\text { Mean duration to second fragility fracture } \\
\text { years }\end{array}$ & 3.9 years & 3.3 & 4.5 & 6.0 & \\
\hline $\begin{array}{l}\text { Patients not treated to guidance after } 2 \text { nd } \\
\text { fracture } \%(\mathrm{n})\end{array}$ & $(11 / 30)$ & None & $(1 / 4)$ & None & \\
\hline
\end{tabular}

*p-value computed from difference in proportions test.

The total numbers of Hip fractures were 24. The trend in the hip fractures in the general practice cohort in the last 10 years has been upward as shown in the Figure 1.

\section{Quality initiatives}

Based on the above results, $43.6 \%(n=137 / 314)$ patients were discussed as part of quality initiatives. A total of 84 active interventions were taken collectively in 60 patients out of 137 patients discussed to ensure bone health is assessed and patients are treated to guidance. The CBD took approximately 14 hours over 6 working days, spread over 4 weeks to discuss 137 patients. The lists of interventions taken are shown in Table 4.

$56 \%(n=175 / 314)$ had a recorded diagnoses of osteoporosis in the GP database but $39 \%(68 / 175)$ of these had no evidence of fragility fracture or low BMD on DXA scan. All these patients were reviewed and the majority $(68 \%, 46 / 68)$ were on appropriate treatment for 
primary osteoporosis. As part of quality initiatives, 11 patients were commenced on new oral bisphosphonates but 5 patients were on osteoporosis drugs inappropriately and were stopped. Four patients were considered for drug holiday and two patients were considered for specialist treatment (Denosumab) as noted to have worsening t-scores on existing repeat DXA report (Table 4).

Table 4 List of the interventions taken as part of quality improvement.

\begin{tabular}{|c|c|c|}
\hline \multicolumn{3}{|c|}{ Quality improvement interventions } \\
\hline \multirow{7}{*}{ Changes in Drug } & New oral Bisphosphonates recommended & $(24 / 137)$ \\
\hline & Planned for drug holiday & $(15 / 137)$ \\
\hline & Considered for Denosumab & $(12 / 137)$ \\
\hline & Stopped as not indicated & $(8 / 137)$ \\
\hline & Refused treatment & $(1 / 137)$ \\
\hline & Replaced to Alfacalcidol & $(1 / 137)$ \\
\hline & No drug intervention & $(45 / 137)$ \\
\hline \multirow{2}{*}{ Referrals } & Bone Health clinic for Denosumab & $(6 / 137)$ \\
\hline & Community Falls and Bone Health team & $(6 / 137)$ \\
\hline \multirow{3}{*}{ Investigations } & Re-refer for DXA (planned for future) & $(11 / 137)$ \\
\hline & New DXA & $(5 / 137)$ \\
\hline & Blood tests & $(7 / 137)$ \\
\hline
\end{tabular}

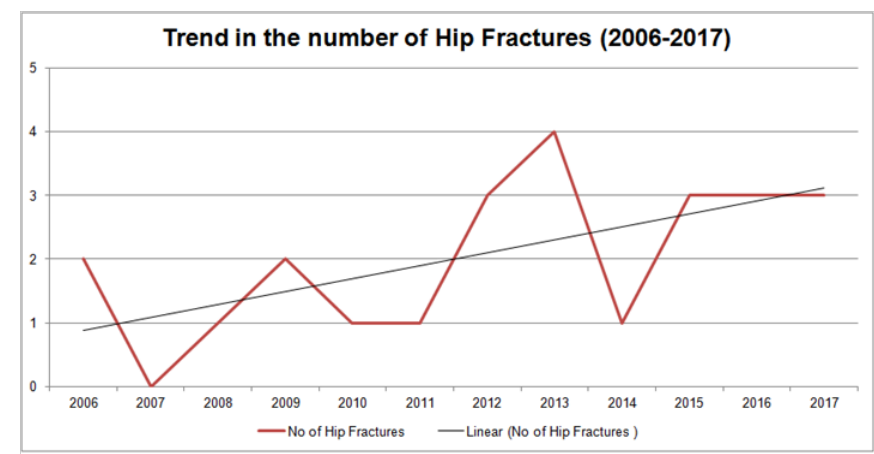

Figure 1 Trend in the hip fracture over the last 10 years.

Another 12.4\% ( $\mathrm{n}=39 / 314)$ patients had not been recorded as osteoporosis in the GP database but were found to had a history of fracture of which $68 \%(n=23 / 39)$ will be classed as fragility fractures including vertebra, wrist, hip, pelvis and humerus. All these 23 patients were reviewed as part of the quality initiatives and 54\% $(13 / 23)$ patients were commenced on oral treatment and others were either referred to Bone Health clinic or further investigations.

A further 17 patients who had diagnoses of both osteoporosis and previous fragility fracture but were not on osteoporosis drugs due to various reasons including poor adherence, side effects, drug holidays. Thirteen patients were considered for clinical assessment or DXA scan if indicated and four patients were considered for specialist treatment (Denosumab) through Bone Health Clinic.

All the 19\% (17/89) patients who were on treatment for more than 5 years were also discussed, 11 were considered for drug holiday and in three patients treatment was stopped. Two patients were continued to treat for longer duration's years but with close monitoring for side effects, one patient was deemed as treatment failure in view of the second fragility and was referred to Bone Health clinic.

\section{Discussion}

Osteoporosis is an asymptomatic, hidden condition, and often diagnosed after sustaining a fragility fracture. An osteoporotic fracture is a fragility fracture following a fall from a standing height or less, occurring as a consequence of underlying osteoporosis in the wrist, spine, and hip, but can also occur in the humerus, pelvis, ribs, and other bones. ${ }^{10}$ However vertebral fractures may occur as a result of routine activity, bending, lifting, after a minimal trauma or even spontaneously. All general practices and secondary care services in the United Kingdom should ensure that a system is in place for patients above 50 years of age but less than 75 years with a history of fragility fracture to be confirmed on DXA and treated to guidance. ${ }^{10,12,16}$ All patients above 75 years with recorded fragility fractures should be assessed $^{17}$ and treated for osteoporosis to guidance. ${ }^{10,12}$ Patients should also be assessed for future risk of fragility fractures and bisphosphonates should be discontinued after 5 years as this does not appear to significantly increase fracture risk. ${ }^{18}$ However, those at a very high risk of falls or sustaining a clinical vertebral fracture could be offered treatment beyond 5 years with close monitoring rather than follow-up measurements of DXA or bone turn over markers. ${ }^{19}$

Vertebral fractures were the most common fragility fracture noted in this study and fractures were more common in over 75 years, significantly higher for females. Our findings are similar to previously reported findings. ${ }^{20}$ The incidence of the second fracture following index fracture (hip, shoulder, or wrist) within a year above 66 years in U.S. population has been reported as $4.2 \% .^{21}$ However in this study, the incidence of the second fracture following index fracture (hip, vertebra, wrist, humerus or pelvis) within a year was $24 \%$ and onethird of the patients sustained a second fracture with a mean duration of 4 years. This could be due to several unexplored factors and a recent study has reported substantial geographic heterogeneity in age and sex-adjusted fracture incidence. ${ }^{22}$ 
In this study, we found that prevalence of fragility fracture in the patients studied according to Quality and Outcomes Framework of the General Medical Services contract was $37 \%$, which is $1.8 \%$ $(n=116 / 6300)$ of the whole practice population. One-third $(34.5 \%$, $\mathrm{n}=40 / 116)$ patients were not treated to guidance. But as part of quality initiative 24 patients were commenced on oral treatment and 6 were considered for Denosumab treatment, suggesting an overall improvement by $75 \%$ for those who were not on evidence-based treatment. Another 7.3\% (23/314) patients in the whole practice cohort were prescribed osteoporosis drugs inappropriately, who were either stopped or considered for drug holiday as per guidance. This study has strengthened the integration and partnership working between primary and secondary care. Majority of the patients were managed in the practice and practice doctors felt more confident and competent to manage osteoporosis.

The emergency hospital admissions in the Caerphilly County Borough with a primary diagnosis of hip fracture for all persons aged 65 and over in year 2014/15 were $185 .{ }^{23}$ This study has also observed an upward trend in the hip fracture for the practice population (Figure 1). The average hip fractures in the same Borough in the last 10 years $(2005 / 05$ to $2014 / 15)$ was 174 (range $=148-193)$, showing an upward trend. ${ }^{23}$ Based on the 2011 census, population estimate for Caerphilly County Borough is 178,806 and 69131 people will be above 50 years, at risk of fracture. ${ }^{24}$ The estimated number of fragility fracture as extracted from the National Osteoporosis Society Fracture Liaison Service benefits calculator would be 802 , including 189 hip fractures. ${ }^{25}$ The current guidance recommends more integrated care and improved osteoporosis treatment, targeting all patients with fragility fractures but prioritising those who had sustained hip fracture. ${ }^{26}$ This will not only improve lives but will also be very cost-effective. ${ }^{26}$

This pilot study has several strengths. Scoping was carried out an early stage in order to plan this study and the General Practice staff was involved to identify the key issues. The results of the scoping determined that existing osteoporosis burden and gaps in the osteoporosis care within the General Practice were studied before implementing previously reported quality initiatives to improve osteoporosis care. We are not aware of any similar study which has reported scaling to underpin the number of patient encounters (137 CBD) and timespan (baseline data collection and cleaning = 200 hours, data analysis, quality improvement work $=40$ hours and interpretation $=10$ hours) needed to ensure osteoporosis treatment is addressed in an average General Practice serving a population of 6000 . This study supports previously reported improvement in osteoporosis care using similar quality initiatives but in a different environment. Therefore, this study does not only streamline the process but also maximise the understanding of osteoporosis care and potential to provide an enhanced autonomous osteoporosis care by the General Practice doctors. This study has further established generalisability and increased the potential to spread good practice to other clinical areas and specialities.

This study has few limitations. It is low power study as compared to other studies done in the community. Those patients who are not been recorded in the practice as having osteoporosis or previous fragility fracture or on osteoporosis treatment could have been missed. We have not screened everyone above 65 years as per NICE recommendations because the aim of this pilot study was to measure the prevalence of fragility fractures in all patients above 50 years according to QOF of the GMS contract and based on the understanding of the gaps in our service, consider subsequent steps. The long-term benefits of these quality initiatives have not been yet evaluated but will be studied in the future. This was a feasibility study to plan subsequent study on a wider scale to include all the General Practices in the Caerphilly County Borough.

A fragility fracture is often seen as a physical injury but it also has a huge psychological impact on person's life which cannot be measured. The aim should be to avoid a fall resulting in fracture but at least every effort should be made to prevent subsequent fracture by ensuring evidence-based osteoporosis treatment. We proposed a similar study and intervention not only in other practices within the Caerphilly County Borough but as widely as possible. The research team will be evaluating the long-term impact of such intervention in preventing subsequent fracture, particularly a trend in the hip fracture in the defined area.

\section{Conclusion}

This feasibility study suggests that an average practice of 6000 , have approximately $2 \%$ patients with fragility fractures and one-third were not treated to guidance. Regular monitoring of practice data and implementing quality initiatives has streamlined the process, maximizing osteoporosis understanding and an enhanced autonomous osteoporosis care by the general practice doctors. Similar intervention is proposed for the whole of the Borough to prevent a second fracture, particularly a hip fracture.

\section{Acknowledgements}

The authors are grateful to all the members of the Department of Geriatric Medicine, Ysbyty Ystrad Fawr for their continued support for research activities. The authors would especially like to thank Jane Power and Imtiaz Hussain for their immense contribution, as this project would have been impossible without their administrative support. No external funding was applied.

\section{Author contributions}

I.S. designed the study. A.A. and A.R. contributed to data collection. C.E. performed statistical analysis. I.S. and C.E. completed data interpretation. I.S. wrote the first draft. I.S., A.A., N.S., A.H.F., S.M. and A.W. implemented quality initiatives and completed a critical revision of the article. All authors contributed and approved the final version.

\section{Conflict of interest}

The authors declare no conflict of interest.

\section{References}

1. Masi L. Epidemiology of osteoporosis. Clinical Cases in Mineral and Bone Metabolism. 2008;5(1):11-13.

2. Royal College of Physicians, National hip fracture database annual report 2017. London, RCP; 2017.

3. Roche JJW, Wenn RT, Sahota O, et al. Effect of comorbidities and postoperative complications on mortality after hip fracture in elderly people: prospective observational cohort study. BMJ. 2005;331(7529):1374. 
4. Kanis JA, Johnell O, De Laet C, et al, Silman A, Tenenhouse A. A meta-analysis of previous fracture and subsequent fracture risk. Bone. 2004;35(2):375-82.

5. Bliuc D, Alarkawi D, Nguyen TV, et al. Risk of subsequent fractures and mortality in elderly women and men with fragility fractures with and without osteoporotic bone density: the dubbo osteoporosis epidemiology study. J Bone Miner Res. 2015;30(4):637-46.

6. Ramnemark A, Nyberg L, Lorentzon R, et al. Progressive hemiosteoporosis on the paretic side and increased bone mineral density in the nonparetic arm the first year after severe stroke. Osteoporos Int 1999;9(3):269-75.

7. kim hd, kim sh, kim dk, et al. change of bone mineral density and relationship to clinical parameters in male stroke patients. Ann Rehabil Med. 2016;40(6):981-988.

8. Bos F, Speelman AD, Samson M, et al. Parkinson's disease and osteoporosis. Age Ageing. 2013;42(2):156-62.

9. Aithal S, Sequeira, R, Edwards C, et al. Fragility fractures and parkinsonism: relationship of fractures with demography, severity and predictors of adverse outcomes. Geriatrics. 2017;2(2):17.

10. https://www.nice.org.uk/guidance/ta161

11. Singh I, Fletcher R, Scanlon L, et al. A quality improvement initiative on the management of osteoporosis in older people with Parkinsonism. BMJ Open Quality. 2016;5(1):u210921.w5756.

12. http://www.nhsemployers.org/ /media/Employers/Documents/ Primary\%20care\%20contracts/QOF/2016-17/2016-17\%20QOF\%20 guidance $\% 20$ documents.pdf

13. Liu AT, Ashe MC, Graf $\mathrm{P}$, et al. Mild cognitive impairmen increases falls risk in older community-dwelling women. Phys Ther. 2008;88(12):1482-1491.

14. Contreras A, Grandas F. Risk of falls in parkinson's disease: a crosssectional study of 160 patients. Parkinson's Disease. 2012;2012:362572.
15. http://gov.wales/topics/health/nhswales/prudent-healthcare/?lang=en

16. https://cks.nice.org.uk/osteoporosis-prevention-of-fragilityfractures\#!scenario

17. https://www.nice.org.uk/guidance/cg

18. Black, D.M., Schwartz, Ensrud KE, et al. Effects of continuing or stopping alendronate after 5 years of treatment: the Fracture Intervention Trial Long-term Extension (FLEX): a randomized trial. JAMA. 2006;296( 24):2927- 2938.

19. Bauer DC, Schwartz A, Palermo L, et al. Fracture Prediction After Discontinuation of 4 to 5 Years of Alendronate Therapy: The FLEX Study. JAMA internal medicine. 2014;174(7):1126-1134.

20. Tsuda T. Epidemiology of fragility fractures and fall prevention in the elderly: a systematic review of the literature. Curr Orthop Pract. 2017;28(6):580-585.

21. Bynum JPW, Bell JE, Cantu RV, et al. Second fractures among older adults in the year following hip, shoulder or wrist fracture. Osteoporos Int. 2016;27(7):2207-2215.

22. Curtis EM, Velde R, Moon RJ, et al. Epidemiology of fractures in the United Kingdom 1988-2012: Variation with age, sex, geography, ethnicity and socioeconomic status. Bone. 2016;87:19-26.

23. Wales Emergency hospital admissions with a diagnosis of fractured neck of femur, persons aged 65. Data from the Public Health Wales Observatory. 2016.

24. http://www.caerphilly.gov.uk/CaerphillyDocs/Equalities/2011-CensusLocal-Equalities-Data-for-Caerphilly-C.aspx

25. https://benefits.nos.org.uk

26. Ip TP, Leung J, Kung AWC. Management of osteoporosis in patients hospitalized for hip fractures. Osteoporosis International. 2010;21(4):605-614. 